\title{
IL1RN Variation Influences Both Disease Susceptibility and Response to Recombinant Human Interleukin-1 Receptor Antagonist Therapy in Systemic Juvenile Idiopathic Arthritis
}

\author{
Victoria L. Arthur, ${ }^{1}$ Emily Shuldiner, ${ }^{1}$ Elaine F. Remmers, ${ }^{2}$ Anne Hinks, ${ }^{3}$ Alexei A. Grom, ${ }^{4}$ \\ Dirk Foell, ${ }^{5}$ Alberto Martini, ${ }^{6}$ Marco Gattorno,${ }^{6}$ Seza Özen, ${ }^{7}$ Sampath Prahalad, ${ }^{8}$ \\ Andrew S. Zeft, ${ }^{9}$ John F. Bohnsack, ${ }^{10}$ Norman T. Ilowite (D), ${ }^{11}$ Elizabeth D. Mellins, ${ }^{12}$ \\ Ricardo Russo, ${ }^{13}$ Claudio Len, ${ }^{14}$ Sheila Oliveira, ${ }^{15}$ Rae S. M. Yeung, ${ }^{16}$ Alan M. Rosenberg, ${ }^{17}$ \\ Lucy R. Wedderburn ${ }^{18}$ Jordi Anton, ${ }^{19}$ Johannes-Peter Haas, ${ }^{20}$ Angela Rösen-Wolff, ${ }^{21}$ \\ Kirsten Minden, ${ }^{22}$ Ann Marie Szymanski, ${ }^{1}$ INCHARGE Consortium, Wendy Thomson, ${ }^{23}$ \\ Daniel L. Kastner, ${ }^{2}$ Patricia Woo, ${ }^{24}$ and Michael J. Ombrello (iD ${ }^{1}$
}

Objective. To determine whether systemic juvenile idiopathic arthritis (JIA) susceptibility loci that were identified by candidate gene studies demonstrate association with systemic JIA in the largest study population assembled to date.

Methods. Single-nucleotide polymorphisms (SNPs) from 11 previously reported systemic JIA risk loci were

The views expressed herein are those of the authors and do not reflect the official views of the National Health Service, the National Institute for Health Research, or the UK Department of Health.

Supported by the NIH (National Institute of Arthritis and Musculoskeletal and Skin Diseases Intramural Research Programs grant Z01-AR-041198 [to Dr. Ombrello] and National Human Genome Research Institute grant Z01-HG-200370 [to Dr. Kastner]). Additional support was provided by NIH grants R01-AR-059049 (to Dr. Grom), R01-AR-061297 (to Dr. Mellins), and R01-AR-060893 (to Dr. Prahalad), Arthritis Research UK (grant 20385 to Dr. Thomson), the German Federal Ministry of Education and Research (BMBF project grants 01ER0813 and 01ER0812 [to Drs. Minden and Foell] and 01ER0828 [to Dr. Minden]), the Val A. Browning Charitable Foundation (grant to Dr. Bohnsack), and the Marcus Foundation (grant to Dr. Prahalad). Drs. Thomson and Hinks' work was supported by the Manchester Academic Health Sciences Centre and the NIHR Biomedical Research Unit Funding Scheme. Dr. Wedderburn's work was supported by the NIHR Great Ormond Street Hospital Biomedical Research Centre.

${ }^{1}$ Victoria L. Arthur, BA, Emily Shuldiner, BA, Ann Marie Szymanski, MD, Michael J. Ombrello, MD: National Institute of Arthritis and Musculoskeletal and Skin Diseases, NIH, Bethesda, Maryland; ${ }^{2}$ Elaine F. Remmers, PhD, Daniel L. Kastner, MD, PhD: National Human Genome Research Institute, NIH, Bethesda, Maryland; ${ }^{3}$ Anne Hinks, PhD: Arthritis Research UK Centre for Genetics and Genomics, Centre for Musculoskeletal Research, University of Manchester, Manchester, UK; ${ }^{4}$ Alexei A. Grom, MD: University of Cincinnati College of Medicine and Cincinnati Children's Hospital Medical Center, Cincinnati, Ohio; ${ }^{5}$ Dirk Foell, MD: University Hospital Münster, Münster, Germany; ${ }^{6}$ Alberto Martini, MD, Marco Gattorno, MD: G. Gaslini Institute and University of Genoa, Genoa, Italy; ${ }^{7}$ Seza Özen, MD: Hacettepe University, Ankara, Turkey; ${ }^{8}$ Sampath Prahalad, MD: Emory University School of Medicine and Children's examined for association in 9 populations, including 770 patients with systemic JIA and 6,947 controls. The effect of systemic JIA-associated SNPs on gene expression was evaluated in silico in paired whole genome and RNA sequencing data from the lymphoblastoid cell lines (LCLs) of 373 European subjects from the $1000 \mathrm{Ge}$ nomes Project. Responses of systemic JIA-associated

Healthcare of Atlanta, Atlanta, Georgia; ${ }^{9}$ Andrew S. Zeft, MD: Cleveland Clinic, Cleveland, Ohio; ${ }^{10}$ John F. Bohnsack, MD: University of Utah, Salt Lake City; ${ }^{11}$ Norman T. Ilowite, MD: Albert Einstein College of Medicine and Children's Hospital at Montefiore, Bronx, New York; ${ }^{12}$ Elizabeth D. Mellins, MD, PhD: Stanford University, Stanford, California; ${ }^{13}$ Ricardo Russo, MD: Hospital de Pediatria Garrahan, Buenos Aires, Argentina; ${ }^{14}$ Claudio Len, MD: Universidade Federal de São Paulo, São Paulo, Brazil; ${ }^{15}$ Sheila Oliveira, MD, PhD: Universidade Federal de Rio de Janeiro, Rio de Janeiro, Brazil; ${ }^{16}$ Rae S. M. Yeung, MD, PhD: University of Toronto, Toronto, Ontario, Canada; ${ }^{17}$ Alan M. Rosenberg, MD: University of Saskatchewan, Saskatoon, Saskatchewan, Canada; ${ }^{18}$ Lucy R. Wedderburn, MD, PhD: University College London and NIHR GOSH Biomedical Research Centre, London, UK; ${ }^{19}$ Jordi Anton, MD, PhD: Hospital Sant Joan de Déu, Universitat de Barcelona, Barcelona, Spain; ${ }^{20}$ Johannes-Peter Haas, MD: German Center for Pediatric and Adolescent Rheumatology, Garmisch-Partenkirchen, Germany; ${ }^{21}$ Angela Rösen-Wolff, MD, PhD: University Hospital Cal Gustav Carus, Dresden, Germany; ${ }^{22}$ Kirsten Minden, MD, PhD: Charité University Medicine and German Rheumatism Research Centre, Berlin, Germany; ${ }^{23}$ Wendy Thomson, PhD: Arthritis Research UK Centre for Genetics and Genomics, Centre for Musculoskeletal Research, NIHR Manchester Biomedical Centre, Central Manchester NHS Foundation Trust, Manchester Academic Health Centre, University of Manchester, Manchester, UK; ${ }^{24}$ Patricia Woo, MBBS, PhD: University College London, London, UK.

Ms Arthur and Ms Shuldiner contributed equally to this work.

Dr. Grom has received consulting fees from Novartis and Novimmune (less than $\$ 10,000$ each). Dr. Martini has received speaking fees from Abbott, AbbVie, Amgen, Baxalta Biosimilars, Biogenidec, Bristol-Myers Squibb, Astellas, Boehringer, Italfarmaco, Janssen, MedImmune, Novartis, NovoNordisk, Pfizer, Sanofi, Roche, Servier, Takeda, and UCB Biosciences (less than $\$ 10,000$ each) and 
SNPs to anakinra treatment were evaluated in $\mathbf{3 8}$ US patients for whom treatment response data were available.

Results. We found no association between the previously reported 26 SNPs and systemic JIA. Expanded analysis of the regions containing the 26 SNPs revealed only 1 significant association: the promoter region of ILIRN $\left(P<1 \times 10^{-4}\right)$. Systemic JIA-associated SNPs correlated with ILIRN expression in LCLs, with an inverse correlation between systemic JIA risk and ILIRN expression. The presence of homozygous ILIRN high expression alleles correlated strongly with a lack of response to anakinra therapy (odds ratio 28.7 [95\% confidence interval 3.2-255.8]).

Conclusion. In our study, $I L 1 R N$ was the only candidate locus associated with systemic JIA. The implicated SNPs are among the strongest known determinants of $I L 1 R N$ and interleukin-1 receptor antagonist levels, linking low expression with increased systemic JIA risk. Homozygous high expression alleles predicted nonresponsiveness to anakinra therapy, making them ideal candidate biomarkers to guide systemic JIA treatment. This study is an important first step toward the personalized treatment of systemic JIA.

Systemic juvenile idiopathic arthritis (JIA) is a rare, severe childhood inflammatory disease $(1,2)$ that develops without an identifiable cause. It is marked by the presence of chronic arthritis that occurs along with profound systemic inflammation, including quotidian fever, lymphadenopathy, hepatosplenomegaly, a salmon pink evanescent skin rash, and serositis. It may also be accompanied by life-threatening complications, including pericardial effusion, interstitial lung disease, amyloidosis, and macrophage activation syndrome - a highly lethal secondary form of hemophagocytic lymphohistiocytosis.

research grants from Abbott, Bristol-Myers Squibb, Francesco Angelini, GlaxoSmithKline, Janssen Biotech, Novartis, Pfizer, Roche, Sanofi, Aventis, and Schwarz Biosciences. Dr. Gattorno has received consulting fees (less than $\$ 10,000$ each) and research grants from Novartis and Sobi. Dr. Prahalad has received consulting fees from Novartis and Medac Pharma (less than \$10,000 each). Dr. Zeft owns stock in Merck Pharmaceuticals, and OPKO. Dr. Ilowite has received consulting fees from Sobi and Novartis (less than $\$ 10,000$ each). Dr. Mellins has received consulting fees (less than $\$ 10,000$ ) and research grants from Novartis. Dr. Minden has received consulting fees from Chugai (less than $\$ 10,000$ ) and research grants from Pfizer, AbbVie, and Roche.

Address correspondence to Michael J. Ombrello, MD, Translational Genetics and Genomics Unit, Intramural Research Program, National Institute of Arthritis and Musculoskeletal and Skin Diseases, NIH, 10 Center Drive, 12N248A, Building 10, MSC1560, Bethesda, MD 20892. E-mail: Michael.Ombrello@nih.gov.

Submitted for publication October 16, 2017; accepted in revised form March 13, 2018.
Among children with systemic JIA, 50\% develop a destructive form of chronic arthritis that persists throughout their lives.

Despite its unifying inflammatory characteristics, systemic JIA is a heterogeneous condition with 3 distinct disease courses and variable expression of clinical manifestations and complications (3). Regardless of the disease course and specific manifestations, the goal of systemic JIA treatment is to extinguish the systemic inflammation as rapidly as possible, taking advantage of the early therapeutic "window of opportunity" in an effort to avoid the development of persistent arthritis (4). Achievement of this goal is often complicated by the fact that children with systemic JIA do not respond uniformly to the currently available therapies $(5,6)$. One subset of patients with systemic JIA responds to treatments targeting interleukin-1 (IL-1), another subset responds to IL-6-directed therapies, another responds to tumor necrosis factor (TNF) blockade, and some do not respond to any of these treatment strategies. Importantly, there is no objective determinant or biomarker that assists in predicting which therapeutic approach will be successful in individual patients, and thus there are often delays in amelioration of the systemic inflammation.

The pathophysiology of systemic JIA is poorly understood, as is the basis of its phenotypic heterogeneity. Due to its rare nature, most genetic studies of systemic JIA have utilized a candidate gene approach to examine small case-control collections. These studies have produced a list of more than 2 dozen single-nucleotide polymorphisms (SNPs) at 11 distinct susceptibility loci that were reported as systemic JIA-associated loci. These include the $I L 1 A / B$ (7,8), GLI2 (7), IL1RN/PSD4 (7), IL1R2 (7), IL10/20 (9,10), IL6 (11,12), MVK (8), CCR5 (13), MIF (14), SLC26A2 (15), and TAPBP (16) loci (Table 1). Importantly, the original evidence supporting these associations was modest and, in many cases, the associations were not observed in studies of independent populations. Despite these facts, these associations are regularly included in discussions of systemic JIA pathophysiology.

We have recently performed the largest genetic study of systemic JIA, a multinational effort that included children with systemic JIA from 9 countries $(17,18)$. We identified 2 bona fide systemic JIA susceptibility loci and 24 additional loci suggestively associated with systemic JIA; however, there was no overlap between the peak systemic JIA susceptibility loci in our studies and those reported in the earlier candidate gene studies. To evaluate the relationship between systemic JIA risk and the systemic JIA susceptibility loci identified in candidate gene studies, we have undertaken a regional association study of the 11 reported candidate susceptibility loci in the 
International Childhood Arthritis Genetics Consortium (INCHARGE; for full membership of the INCHARGE and collaborating consortia, see Appendix A) systemic JIA case-control collection.

\section{PATIENTS AND METHODS}

Study design and participants. Directly observed and imputed SNP genotype data from the 9 case-control populations of the INCHARGE systemic JIA collection $(17,18)$ were evaluated for this study. The INCHARGE systemic JIA collection includes children who fulfill the International League of Associations for Rheumatology criteria for systemic JIA and controls from the US, the UK, Germany, Turkey, Italy, Brazil, Argentina, Canada, and Spain. SNP genotyping of genomic DNA from cases and controls was performed using HumanOmni1M arrays and an iScan reader (Illumina). SNP genotypes were stratified by country of origin and, where available, combined with existing SNP genotype data sets, in silico, from geographically matched healthy controls. Using standard metrics, each geographically defined stratum was subjected to rigorous quality control processes to remove samples and SNPs of poor quality. Ancestral outliers were removed from each of these strata using a combination of principal components analysis and multidimensional scaling. The degree of matching was assessed using genomic control inflation factors $\left(\lambda_{\mathrm{gc}}\right)$, which were $<1.004$ for each of the 9 strata. Detailed information about patient and control populations included in the INCHARGE collection, along with technical descriptions and visualizations of the quality control processes and associated results, can be found in the supplementary material of our earlier reports $(17,18)$.

For the present study, genotypes of SNPs residing in 11 candidate loci (see Supplementary Table 1, available on the Arthritis \& Rheumatology web site at http://onlinelibrary.wiley. com/doi/10.1002/art.40498/abstract) were examined in 770 children with systemic JIA and 6,947 control samples from the US, the UK, Germany, Turkey, Italy, Brazil, Argentina, Canada, and Spain. For candidate loci defined by a single systemic JIA-associated SNP, the study interval was defined as $\pm 100 \mathrm{~kb}$ from the position of that SNP. When $>1$ SNP association was present within a locus, the study interval was defined as $\pm 100 \mathrm{~kb}$ from the mean of the positions of the reported systemic JIA-associated SNPs.

Statistical analysis. Association testing of candidate SNPs was performed under the additive model, adjusted for sex and ancestry-informative principal components, in each of the 9 systemic JIA case-control collections using SNPTEST version 2 (19). Association results were then combined across collections using fixed-effect meta-analysis with GWAMA software (20). Heterogeneity was evaluated using the $\mathrm{I}^{2}$ statistic, and SNPs

Table 1. Association results of 26 systemic JIA candidate SNPs in the INCHARGE study collection*

\begin{tabular}{|c|c|c|c|c|c|c|}
\hline \multirow[b]{2}{*}{ Previous study, SNP/gene } & \multicolumn{2}{|c|}{ Previous study } & \multicolumn{2}{|c|}{ INCHARGE study } & \multirow[b]{2}{*}{$\mathrm{I}^{2}$} & \multirow{2}{*}{$\begin{array}{l}\text { No. of strata/ } \\
\text { no. of samples }\end{array}$} \\
\hline & $P$ & OR $(95 \% \mathrm{CI})$ & $P$ & OR $(95 \% \mathrm{CI})$ & & \\
\hline \multicolumn{7}{|l|}{ Stock et al (7) } \\
\hline rs6712572/IL-1 ligand $(C K A P 2 L)$ & 0.0045 & $1.62(1.16-2.29)$ & 0.66 & $1.03(0.91-1.15)$ & 0.34 & $9 / 7,708$ \\
\hline rs2071374/IL-1 ligand (IL1A) & 0.0060 & $1.65(1.15-2.37)$ & 0.11 & $1.11(0.98-1.25)$ & 0 & 9/7,711 \\
\hline rs3783516/IL-1 ligand (IL1A/IL1B) & 0.0053 & $1.64(1.15-2.27)$ & 0.04 & $1.13(0.80-1.26)$ & 0.30 & 9/7,711 \\
\hline rs4848123/IL-1 ligand $(G L I 2)$ & 0.0030 & $1.70(1.19-2.44)$ & 0.24 & $0.27(0.12-2.38)$ & 0.80 & $2 / 449$ \\
\hline rs3917368/IL-1 ligand (IL1B) & 0.0096 & $1.57(1.11-2.22)$ & 0.18 & $1.08(0.96-1.22)$ & 0.43 & $9 / 7,715$ \\
\hline rs1688075/IL-1 ligand $(I L 1 R N)$ & 0.0089 & $3.04(1.58-5.85)$ & 0.64 & $0.95(0.77-1.17)$ & 0.06 & $8 / 7,603$ \\
\hline rs4849159/IL-1 ligand (PSD4) & 0.040 & $1.61(1.02-2.54)$ & 0.17 & $0.89(0.75-1.05)$ & 0 & $8 / 5,755$ \\
\hline rs6760120/IL-1 ligand (PSD4) & 0.020 & $1.49(1.06-2.21)$ & 0.33 & $0.92(0.77-1.09)$ & 0.19 & $9 / 7,713$ \\
\hline rs12712122/IL-1 receptor (IL1R2) & 0.0031 & $1.71(1.21-2.41)$ & 0.04 & $1.32(1.03-1.69)$ & 0 & $9 / 7,710$ \\
\hline rs4851531/IL-1 receptor (IL1R2) & 0.0087 & $1.59(1.11-2.28)$ & 0.58 & $0.97(0.86-1.09)$ & 0.13 & $9 / 7,708$ \\
\hline \multicolumn{7}{|l|}{ Omoyinmi et al (10) } \\
\hline rs1400986/IL-10 family (IL20) & 0.0004 & $1.53(1.21-1.93)$ & 0.27 & $1.11(0.93-1.32)$ & 0.48 & $8 / 7,519$ \\
\hline rs4129024/IL-10 family (MAPKAPK2) & 0.0027 & $0.68(0.53-0.88)$ & 0.05 & $0.87(0.75-1.00)$ & 0.08 & $9 / 7,712$ \\
\hline \multicolumn{7}{|l|}{ Fife et al (9) } \\
\hline rs1800896/IL-10 family (IL10) & 0.031 & 1.34 (NA) & 0.02 & $1.15(1.02-1.28)$ & 0 & $9 / 7,716$ \\
\hline rs1400986/IL-10 family (IL20) & 0.028 & 1.51 (NA) & 0.27 & $1.11(0.93-1.32)$ & 0.48 & $8 / 7,519$ \\
\hline Fishman et al (11), rs1800795/IL6 & 0.03 & NA & 0.34 & $0.94(0.84-1.06)$ & 0.32 & $9 / 7,710$ \\
\hline \multicolumn{7}{|l|}{ Hinks et al (8) } \\
\hline rs2071374/IL1A & 0.001 & $1.50(1.16-1.92)$ & 0.11 & $1.11(0.98-1.25)$ & 0 & $9 / 7,711$ \\
\hline rs1183613/MVK & 0.03 & $1.34(1.03-1.74)$ & 0.58 & $1.05(0.89-1.23)$ & 0 & $9 / 7,717$ \\
\hline Scheibel et al (13), rs333/CCR5 & 0.004 & NA & 0.16 & $0.86(0.69-1.06)$ & 0.63 & $4 / 7,009$ \\
\hline De Benedetti et al (14), rs755622/MIF & 0.017 & NA & 0.11 & $0.88(0.76-1.03)$ & 0 & $8 / 7,513$ \\
\hline \multicolumn{7}{|l|}{ Lamb et al (15) } \\
\hline rs1541915/SLC26A2 & 0.0003 & $2.3(1.4-3.7)$ & 0.76 & $0.98(0.87-1.11)$ & 0.19 & $8 / 7,516$ \\
\hline rs $245056 / S L C 26 A 2$ & 0.00002 & $2.8(1.7-4.6)$ & 0.72 & $1.03(0.86-1.23)$ & 0.26 & $8 / 7,513$ \\
\hline rs $245055 / S L C 26 A 2$ & 0.004 & $2.5(1.2-5.0)$ & 0.56 & $0.95(0.81-1.12)$ & 0 & $9 / 7,709$ \\
\hline rs $245051 / S L C 26 A 2$ & 0.0005 & $2.3(1.4-3.7)$ & 0.42 & $0.95(0.85-1.07)$ & 0.44 & $9 / 7,708$ \\
\hline rs245076/SLC26A2 & 0.0015 & $2.7(1.3-5.6)$ & 0.46 & $0.94(0.80-1.11)$ & 0 & $9 / 7,715$ \\
\hline rs $8073 / S L C 26 A 2$ & 0.04 & $2.3(0.9-5.6)$ & 0.25 & $0.91(0.77-1.07)$ & 0 & 9/7,714 \\
\hline Bukulmez et al (16), rs2071888/TAPBP & $0.04 \dagger$ & NA & 0.15 & $1.09(0.97-1.22)$ & 0 & 9/7,715 \\
\hline
\end{tabular}

* JIA = juvenile idiopathic arthritis; SNPs = single-nucleotide polymorphisms; INCHARGE = International Childhood Arthritis Genetic Consortium; $\mathrm{OR}=$ odds ratio; $95 \% \mathrm{CI}=95 \%$ confidence interval; IL-1 = interleukin-1; NA = not available.

$\dagger$ Transmission disequilibrium testing was performed. 
exhibiting moderate evidence of heterogeneity $\left(\mathrm{I}^{2}>0.5\right)$ were excluded from our analysis. Association data were visualized using SNP \& Variation Suite 8 (SVS 8; Golden Helix) and custom $\mathrm{R}$ scripts ( $\mathrm{R}$ version 3.4.0). Haplotype analysis and examination of linkage disequilibrium (LD) were performed using Haploview (21). The SNP set was pruned for pairwise LD of $\mathrm{r}^{2}<$ 0.5 by the estimation-maximization method with PLINK (22) to determine the number of independent SNPs in the study. The threshold for study-wide significance was defined using Bonferroni correction for the total number of independent SNPs across all candidate loci.

Gene expression analysis. The effect of systemic JIAassociated SNPs on gene and/or protein expression was examined using the HaploReg v4.1 database (23). The correlation of systemic JIA-associated SNPs with gene expression was investigated by an integrated examination of RNA sequencing and whole- genome sequencing (WGS) data from subjects from the $1000 \mathrm{Ge}-$ nomes Project $(24,25)$. RNA sequencing data from the set of 373 lymphoblastoid cell lines (LCLs) from the 1000 Genomes Project subjects were downloaded from the Geuvadis web site (http://www. geuvadis.org/web/geuvadis/RNAseq-project) and WGS data from the corresponding individuals were downloaded from the 1000 Genomes Project web site (http://www.internationalgenome.org/ data/). RNA sequencing data (normalized reads per kilobase per million) were stratified by systemic JIA risk allele genotype and the difference in relative expression between genotypes was evaluated using the nonparametric Kruskal-Wallis test. Box plots of relative expression were generated using $\mathrm{R}$.

Therapeutic response analysis. The relationship between systemic JIA-associated ILIRN SNPs and therapeutic response to recombinant human IL-1 receptor antagonist (IL-1Ra) (anakinra) or tocilizumab treatment was examined in
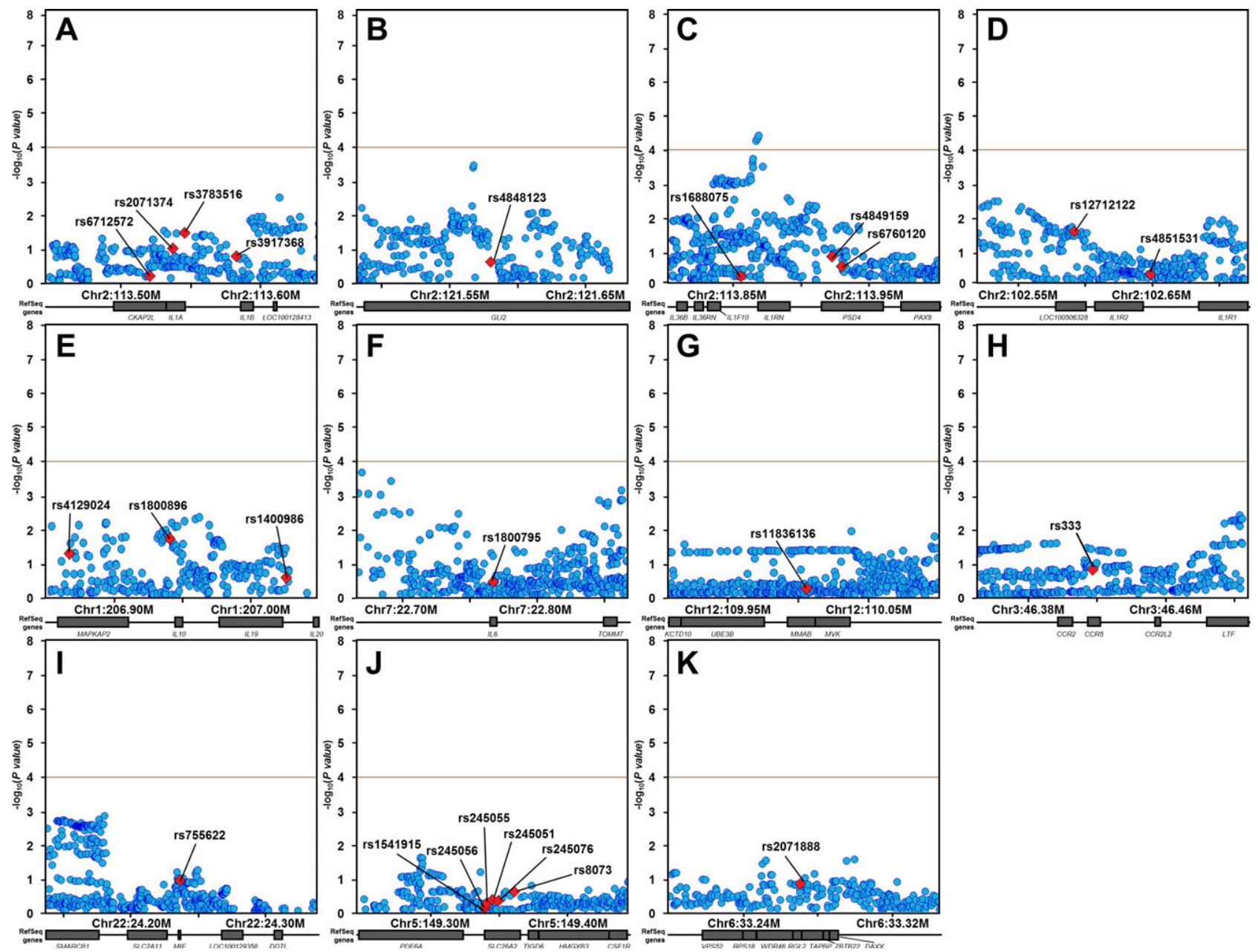

Figure 1. International Childhood Arthritis Genetics Consortium (INCHARGE) systemic juvenile idiopathic arthritis (JIA) case-control regional association plots of loci previously implicated by candidate gene studies. Regional association plots for previously reported systemic JIA candidate susceptibility loci near IL1A/B (A), GLI2 (B), IL1RN/PSD4 (C), IL1R2 (D), IL10/20 (E), IL6 (F), MVK (G), CCR5 (H), MIF (I), SLC26A2 (J), and TAPBP (K) show minimal significance in the INCHARGE case-control data set, except for a cluster of single-nucleotide polymorphisms (SNPs) in the IL1RN/PSD4 region (C). Red diamonds show the top SNPs from previous candidate studies, none of which showed even nominal association with systemic JIA in the INCHARGE cohort. Each blue circle represents the other individual SNPs in the candidate loci. Horizontal lines show the study-wide significance threshold. Chr. = chromosome. 
patients with systemic JIA from the US stratum, for whom therapeutic response data were available. This included 38 patients treated with anakinra and 14 patients treated with tocilizumab. Treatment response data were extracted from medical records by the treating pediatric rheumatologist, who encoded either "no response" or "any response" for each subject. "No response" was defined as no improvement of either fever (if present) or arthritis. "Any response" was defined as any degree of improvement in either fever or arthritis. We then tested for association between treatment response and systemic JIA-associated SNPs by logistic regression under the dominant model, using SVS 8. The threshold of significance for the association test was defined by Bonferroni correction for the number of independent SNPs tested, as defined by pairwise LD pruning $\left(\mathrm{r}^{2}<0.5\right)$.

\section{RESULTS}

Association testing of systemic JIA candidate SNPs and loci. We first performed association testing on the 26 SNPs for which associations with systemic JIA had been previously reported (Table 1). After application of Bonferroni correction for the $26 \mathrm{SNPs}$, association meta-analysis of the 9 INCHARGE systemic JIA study populations revealed no significant associations with systemic JIA $(P<$ $0.05 / 26\left[1.9 \times 10^{-3}\right]$ ) (Table 1 and Supplementary Figure 1, available on the Arthritis \& Rheumatology web site at http:// onlinelibrary.wiley.com/doi/10.1002/art.40498/abstract). To evaluate whether the 11 candidate loci containing these 26 SNPs harbored systemic JIA risk SNPs distinct from those previously described, we extended our analysis to test all SNPs within these candidate risk loci for association with systemic JIA. The candidate regions included a total of 5,479 SNPs (see Supplementary Table 1, available at http:// onlinelibrary.wiley.com/doi/10.1002/art.40498/abstract), but LD pruning at a level of $\mathrm{r}^{2}<0.5$ determined that only 500 of the SNPs were independent. This defined the threshold of study-wide significance $\left(P<0.05 / 500\left[1.0 \times 10^{-4}\right]\right)$. By this standard, association meta-analyses of these 11 loci revealed a single significant association signal within the $I L 1 R N$ locus (Figure 1). The association peak was located $4.3 \mathrm{~kb}$ upstream from $I L 1 R N$, with 3 SNPs exceeding the

B rs55663133 (AAT allele)
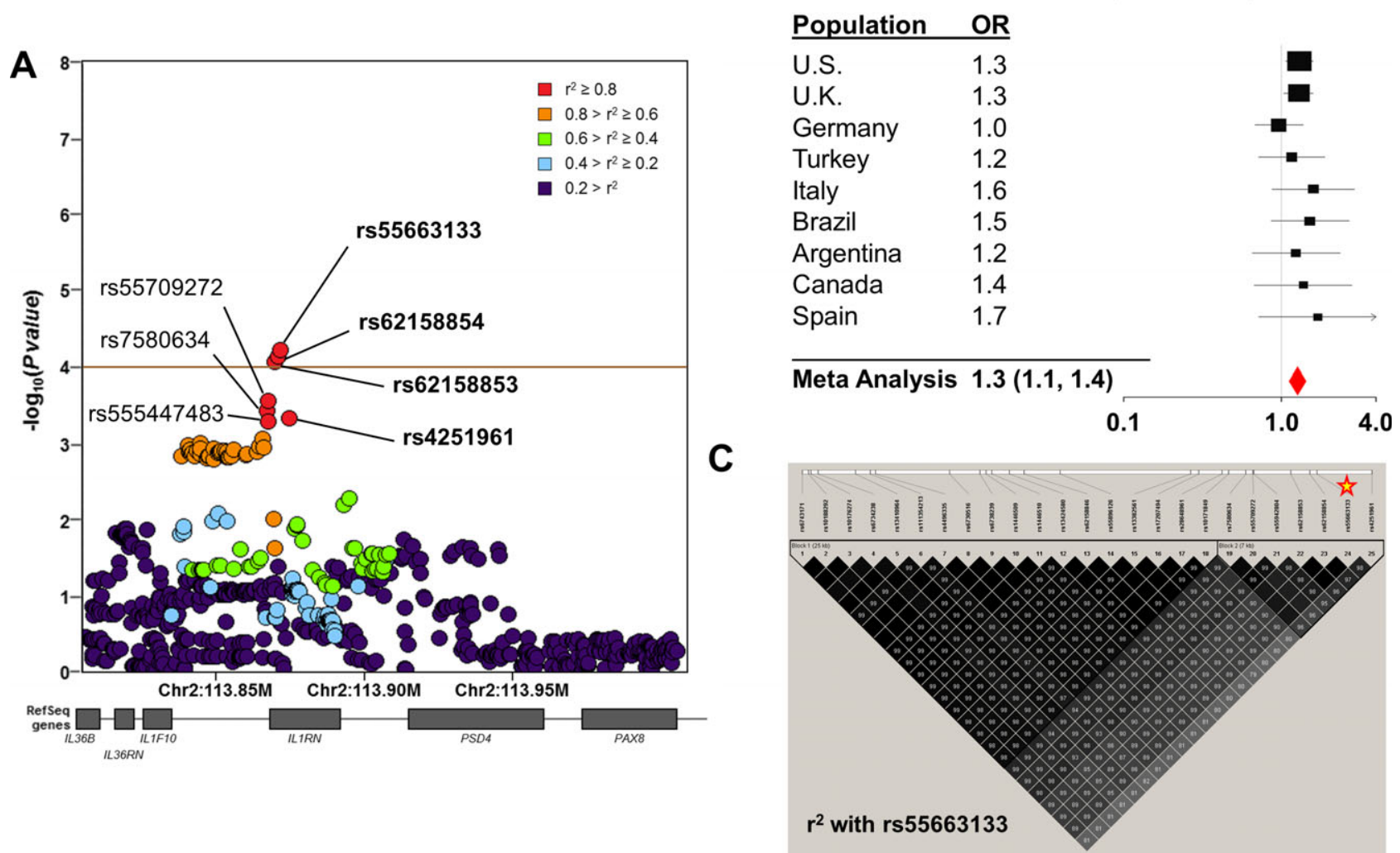

Figure 2. Association between variants of the IL1RN locus and systemic JIA in the INCHARGE case-control collection. A, SNP associations within the $I L 1 R N$ locus, colored according to pairwise linkage disequilibrium (LD) with the most strongly associated SNP, rs55663133. Horizontal line shows the study-wide significance threshold. B, Forest plot demonstrating the effect size of rs55663133 by meta-analysis and in individual study populations. Red diamond indicates the odds ratio (OR) and 95\% confidence interval (95\% CI) from the meta-analysis. Horizontal lines represent the individual populations. Values in parentheses are the 95\% CI. confidence interval. C, Pairwise LD with the peak systemic JIA-associated SNP, rs55663133 (star) in the US case-control population. The top 7 systemic JIA-associated markers (19-25) form a strong LD block. See Figure 1 for other definitions. 
significance threshold and the top 7 SNPs in strong LD with one another (Figure 2). In fact, LD mapping and haplotype analysis of the top 25 SNPs within this locus revealed that the top 7 systemic JIA-associated SNPs were inherited as a part of a common haplotype (Figure 2).

Systemic JIA-associated ILIRN variants and gene expression. A query of the HaploReg version 4.1 database revealed that many of the top systemic JIA-associated SNPs were known expression quantitative trait loci for ILIRN in whole blood (26) and LCLs (25) (Table 2). Moreover, a review of the literature showed that systemic JIA-associated SNPs also correlated with IL-1Ra protein levels in the largest study of genetic predictors of IL-1Ra levels (27). The SNP that most strongly correlated with IL-1Ra in that study, rs4251961, was one of the top systemic JIA-associated SNPs and was a constituent of the 7 SNP haplotypes (Figure 2 and Table 2). These observations were corroborated by our direct analyses of LCL RNA-sequencing data from 1000

Table 2. Association of $I L 1 R N$ SNPs with systemic JIA risk and their effect on $I L 1 R N$ expression/IL-1Ra concentration*

\begin{tabular}{|c|c|c|c|c|c|c|c|c|c|}
\hline \multirow[b]{2}{*}{$\mathrm{SNP} /$ risk allele } & \multirow[b]{2}{*}{ Meta $P \dagger$} & \multirow[b]{2}{*}{$\begin{array}{l}\text { Meta OR } \\
(95 \% \mathrm{CI}) \dagger\end{array}$} & \multirow[b]{2}{*}{$r^{2}+$} & \multicolumn{2}{|c|}{$\begin{array}{c}I L 1 R N \text { in LCLs } \\
\text { (Lappalainen et al } \\
[25])\end{array}$} & \multicolumn{2}{|c|}{$\begin{array}{l}I L 1 R N \text { in whole blood } \\
\text { (Westra et al [26]) }\end{array}$} & \multicolumn{2}{|c|}{$\begin{array}{l}\text { IL-1Ra in serum } \\
\text { (Herder et al [27]) }\end{array}$} \\
\hline & & & & $P$ & $\begin{array}{l}\text { Effect } \\
\text { size }\end{array}$ & $P$ & $\begin{array}{l}\text { Effect } \\
\text { size }\end{array}$ & $P$ & $\begin{array}{l}\text { Effect } \\
\text { size }\end{array}$ \\
\hline rs55663133/AAT§ & $5.9 \times 10^{-5}$ & $1.3(1.1-1.4)$ & 1 & $1.0 \times 10^{-6}$ & -0.25 & - & - & - & - \\
\hline $\mathrm{rs} 62158854 / \mathrm{G} \S$ & $7.2 \times 10^{-5}$ & $1.3(1.1-1.4)$ & 1 & $6.5 \times 10^{-7}$ & -0.25 & - & - & - & - \\
\hline rs62158853/T§ & $8.3 \times 10^{-5}$ & $1.3(1.1-1.4)$ & 1 & $2.6 \times 10^{-7}$ & -0.26 & - & - & - & - \\
\hline rs55709272/Cß & $2.8 \times 10^{-4}$ & $1.2(1.1-1.4)$ & 0.87 & - & - & - & - & - & - \\
\hline rs7580634/ T§ & $3.7 \times 10^{-4}$ & $1.2(1.1-1.4)$ & 0.91 & $2.8 \times 10^{-6}$ & -0.24 & - & - & - & - \\
\hline rs4251961/C $\S$ & $4.6 \times 10^{-4}$ & $1.2(1.1-1.4)$ & 0.86 & $1.0 \times 10^{-6}$ & -0.25 & $1.6 \times 10^{-11}$ & -6.74 & $2.2 \times 10^{-34}$ & -0.08 \\
\hline rs555447483/A $\S$ & $5.0 \times 10^{-4}$ & $1.2(1.1-1.4)$ & 0.89 & - & - & - & - & - & - \\
\hline rs28648961/A & $8.5 \times 10^{-4}$ & $1.2(1.1-1.4)$ & 0.75 & $2.8 \times 10^{-6}$ & -0.24 & - & - & - & - \\
\hline rs111354213/- & $9.8 \times 10^{-4}$ & $1.2(1.1-1.4)$ & 0.74 & - & - & - & - & - & - \\
\hline rs6743171/C & $1.1 \times 10^{-3}$ & $1.2(1.1-1.4)$ & 0.77 & $3.2 \times 10^{-6}$ & -0.24 & $5.8 \times 10^{-8}$ & -5.42 & $6.4 \times 10^{-13}$ & -0.09 \\
\hline rs17207494/C & $1.1 \times 10^{-3}$ & $1.2(1.1-1.4)$ & 0.75 & $2.9 \times 10^{-6}$ & -0.24 & $3.8 \times 10^{-8}$ & -5.50 & $1.3 \times 10-^{11}$ & -0.08 \\
\hline rs10171849/C & $1.1 \times 10^{-3}$ & $1.2(1.1-1.4)$ & 0.75 & $5.5 \times 10^{-6}$ & -0.23 & $2.6 \times 10^{-8}$ & -5.57 & $1.4 \times 10^{-11}$ & -0.08 \\
\hline $\mathrm{rs} 4496335 / \mathrm{T}$ & $1.2 \times 10^{-3}$ & $1.2(1.1-1.4)$ & 0.77 & $3.0 \times 10^{-6}$ & -0.24 & $5.2 \times 10^{-8}$ & -5.44 & $6.4 \times 10^{-13}$ & -0.09 \\
\hline rs6730516/T & $1.2 \times 10^{-3}$ & $1.2(1.1-1.4)$ & 0.77 & $3.5 \times 10^{-6}$ & -0.24 & $6.2 \times 10^{-8}$ & -5.41 & $6.4 \times 10^{-13}$ & -0.09 \\
\hline rs55896126/C & $1.2 \times 10^{-3}$ & $1.2(1.1-1.4)$ & 0.75 & $2.7 \times 10^{-6}$ & -0.24 & - & - & - & - \\
\hline rs6734238/G & $1.2 \times 10^{-3}$ & $1.2(1.1-1.4)$ & 0.73 & - & - & $2.4 \times 10^{-8}$ & -5.58 & $1.1 \times 10^{-12}$ & -0.08 \\
\hline rs13410964/A & $1.2 \times 10^{-3}$ & $1.2(1.1-1.4)$ & 0.77 & $2.7 \times 10^{-6}$ & -0.24 & $6.4 \times 10^{-8}$ & -5.41 & $6.4 \times 10^{-13}$ & -0.09 \\
\hline rs13424580/A & $1.2 \times 10^{-3}$ & $1.2(1.1-1.4)$ & 0.75 & $2.4 \times 10^{-6}$ & -0.24 & $5.3 \times 10^{-8}$ & -5.44 & $1.4 \times 10^{-11}$ & -0.08 \\
\hline rs1446510/T & $1.2 \times 10^{-3}$ & $1.2(1.1-1.4)$ & 0.77 & $2.8 \times 10^{-6}$ & -0.24 & $6.2 \times 10^{-8}$ & -5.41 & $6.5 \times 10^{-13}$ & -0.09 \\
\hline rs10176274/G & $1.3 \times 10^{-3}$ & $1.2(1.1-1.4)$ & 0.77 & $2.7 \times 10^{-6}$ & -0.24 & $5.8 \times 10^{-8}$ & -5.42 & $6.4 \times 10^{-13}$ & -0.09 \\
\hline rs10188292/T & $1.3 \times 10^{-3}$ & $1.2(1.1-1.4)$ & 0.77 & $2.6 \times 10^{-6}$ & -0.24 & $5.8 \times 10^{-8}$ & -5.42 & $6.4 \times 10^{-13}$ & -0.09 \\
\hline rs1446509/T & $1.3 \times 10^{-3}$ & $1.2(1.1-1.4)$ & 0.77 & $2.0 \times 10^{-6}$ & -0.24 & $6.2 \times 10^{-8}$ & -5.41 & $6.5 \times 10^{-13}$ & -0.09 \\
\hline rs62158846/T & $1.3 \times 10^{-3}$ & $1.2(1.1-1.4)$ & 0.75 & - & - & - & - & - & - \\
\hline rs6738239/A & $1.3 \times 10^{-3}$ & $1.2(1.1-1.4)$ & 0.77 & $4.7 \times 10^{-6}$ & -0.23 & $6.1 \times 10^{-8}$ & -5.42 & $6.5 \times 10^{-13}$ & -0.09 \\
\hline rs13382561/G & $1.3 \times 10^{-3}$ & $1.2(1.1-1.4)$ & 0.75 & $1.9 \times 10^{-6}$ & -0.24 & $3.7 \times 10^{-8}$ & -5.51 & $1.4 \times 10^{-11}$ & -0.08 \\
\hline rs7587033/G & 0.001296 & $1.2(1.1-1.4)$ & 0.77 & $2.9 \times 10^{-6}$ & -0.24 & - & - & - & - \\
\hline rs6750559/A & 0.001325 & $1.2(1.1-1.4)$ & 0.77 & $2.5 \times 10^{-6}$ & -0.24 & $6.1 \times 10^{-8}$ & -5.42 & $6.4 \times 10^{-13}$ & -0.09 \\
\hline rs7574427/A & 0.001344 & $1.2(1.1-1.4)$ & 0.77 & $2.1 \times 10^{-6}$ & -0.24 & $4.3 \times 10^{-8}$ & -5.48 & $1.4 \times 10^{-11}$ & -0.08 \\
\hline rs6722922/T & 0.001374 & $1.2(1.1-1.4)$ & 0.77 & $2.7 \times 10^{-6}$ & -0.24 & $6.1 \times 10^{-8}$ & -5.42 & $6.4 \times 10^{-13}$ & -0.09 \\
\hline rs6741180/A & 0.001376 & $1.2(1.1-1.4)$ & 0.77 & $3.1 \times 10^{-6}$ & -0.24 & $6.0 \times 10^{-8}$ & -5.42 & $6.4 \times 10^{-13}$ & -0.09 \\
\hline rs7574159/A & 0.001393 & $1.2(1.1-1.4)$ & 0.75 & $2.1 \times 10^{-6}$ & -0.24 & $5.3 \times 10^{-8}$ & -5.44 & $1.2 \times 10^{-11}$ & -0.08 \\
\hline rs13398728/C & 0.001434 & $1.2(1.1-1.4)$ & 0.77 & $2.7 \times 10^{-6}$ & -0.24 & $6.0 \times 10^{-8}$ & -5.42 & $6.4 \times 10^{-13}$ & -0.09 \\
\hline rs13409371/A & 0.001445 & $1.2(1.1-1.4)$ & 0.79 & $6.3 \times 10^{-7}$ & -0.25 & $5.2 \times 10^{-9}$ & -5.84 & $3.8 \times 10^{-12}$ & -0.08 \\
\hline rs13409360/A & 0.001467 & $1.2(1.1-1.4)$ & 0.79 & $6.5 \times 10^{-7}$ & -0.25 & $3.8 \times 10^{-9}$ & -5.89 & $7.8 \times 10^{-13}$ & -0.08 \\
\hline rs12329129/A & 0.001468 & $1.2(1.1-1.4)$ & 0.77 & $2.8 \times 10^{-6}$ & -0.24 & $6.1 \times 10^{-8}$ & -5.42 & $6.4 \times 10^{-13}$ & -0.09 \\
\hline rs12328368/G & 0.001473 & $1.2(1.1-1.4)$ & 0.77 & $2.7 \times 10^{-6}$ & -0.24 & $6.1 \times 10^{-8}$ & -5.42 & $6.4 \times 10^{-13}$ & -0.09 \\
\hline rs7596350/G & 0.001475 & $1.2(1.1-1.4)$ & 0.75 & $1.7 \times 10^{-6}$ & -0.24 & - & - & - & - \\
\hline rs6746979/A & 0.001485 & $1.2(1.1-1.4)$ & 0.75 & $2.1 \times 10^{-6}$ & -0.24 & $5.1 \times 10^{-8}$ & -5.45 & $1.4 \times 10^{-11}$ & -0.08 \\
\hline rs58865280/A & 0.001494 & $1.2(1.1-1.4)$ & 0.75 & - & - & - & - & - & - \\
\hline rs9973741/G & 0.001514 & $1.2(1.1-1.4)$ & 0.75 & $2.1 \times 10^{-6}$ & -0.24 & - & - & - & - \\
\hline rs $12328766 / G$ & 0.001562 & $1.2(1.1-1.4)$ & 0.77 & $3.0 \times 10^{-6}$ & -0.24 & $6.2 \times 10^{-8}$ & -5.41 & $6.4 \times 10^{-13}$ & -0.09 \\
\hline rs550593914/T & 0.001593 & $1.2(1.1-1.4)$ & 0.77 & - & - & - & - & - & - \\
\hline
\end{tabular}

* IL-1Ra = IL-1 receptor antagonist; LCLs = lymphoblastoid cell lines (see Table 1 for other definitions).

$\dagger$ From fixed effect meta-analysis.

+ Pairwise $\mathrm{r}^{2}$ with rs55663133 using the estimation-maximization method in the US case-control population.

$\S$ The top 7 systemic JIA-associated SNPs, which are inherited as a linkage disequilibrium block. 
Genomes Project subjects (25), which showed that the systemic JIA-associated SNPs were strongly correlated with $I L 1 R N$ expression (Figure 3; also see Supplementary Figure 2, available on the Arthritis \& Rheumatology web site at http://onlinelibrary.wiley.com/doi/10.1002/art.40498/abstract). Specifically, alleles that were protective against systemic JIA correlated with high ILIRN expression and those that were risk factors for systemic JIA correlated with decreased ILIRN expression (Figure 3). Importantly, all
3 of the studies mentioned above parsimoniously demonstrated that systemic JIA risk alleles of the top 42 systemic JIA-associated SNPs were correlated with decreased levels of ILIRN expression or circulating IL-1Ra protein (Figure 3).

Systemic JIA-associated $I L I R N$ variants and response to anakinra therapy in systemic JIA. Given that the response of systemic JIA to treatment with recombinant human IL-1Ra (anakinra) is variable, we hypothesized
A

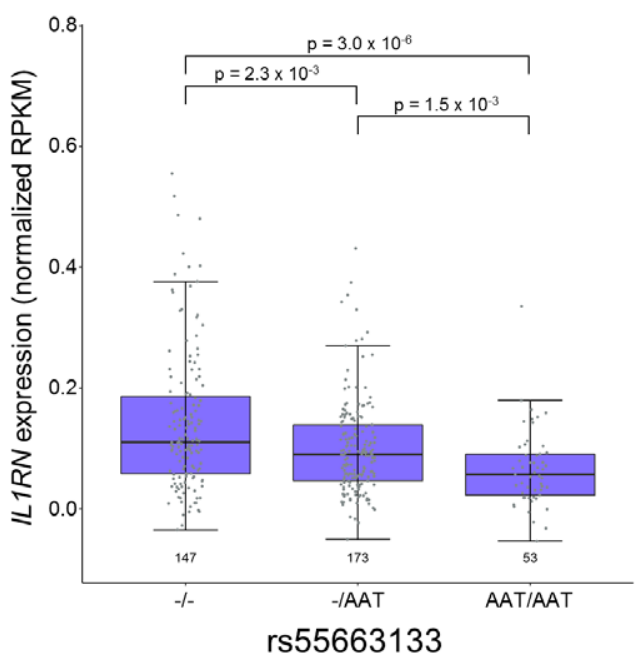

B

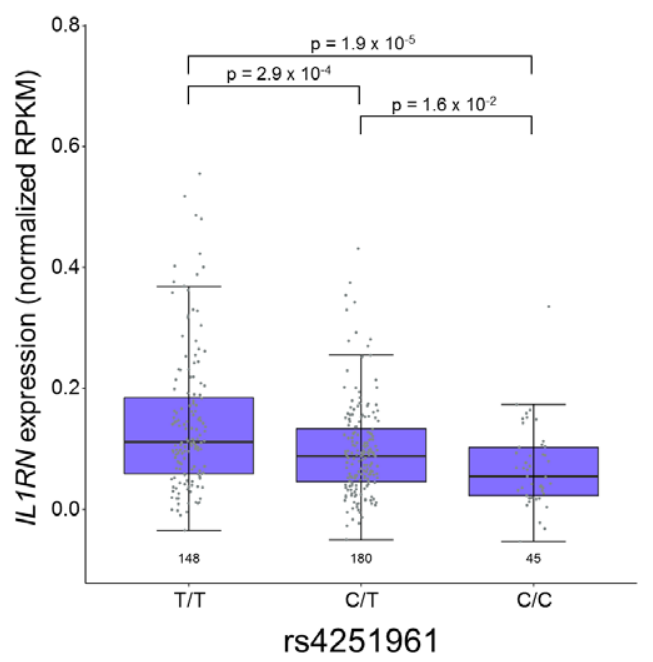

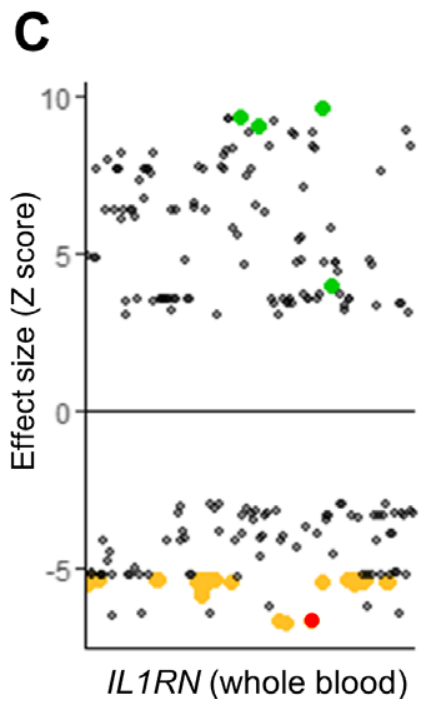

D

$\mathbf{E}$
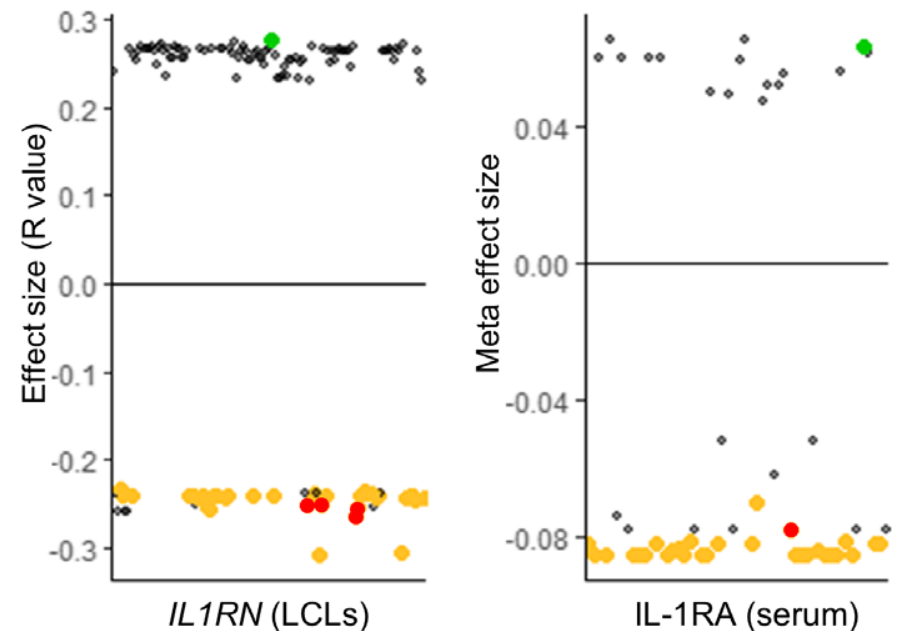

Figure 3. Relationship of $I L 1 R N$ expression and interleukin-1 receptor antagonist (IL-1Ra) protein levels with systemic JIA-associated SNPs. A and B, IL1RN expression determined by RNA sequencing (Lappalainen et al [25]) is shown, stratified by genotype, for representative systemic JIA-associated SNPs. Data are shown as box plots. Each symbol represents a single patient. Boxes represent the 25th to 75th percentiles. Lines inside the boxes represent the median. Lines outside the boxes represent the 10th and 90th percentiles. C-E, Dot plots depicting all SNPs with reported correlations with IL1RN expression (C and D) or IL-1Ra protein levels (E) (Westra et al [26], Lappalainen et al [25], and Herder et al [27], respectively). SNPs among the top 42 systemic JIA-associated SNPs are shown in green (systemic JIA protective alleles) and gold (systemic JIA risk alleles), and the top 7 systemic JIA-associated SNPs are shown in red. Horizontal lines represent the median. RPKM = reads per kilobase per million; LCLs = lymphoblastoid cell lines (see Figure 1 for other definitions). 
Table 3. Association between systemic JIA-associated quantitative trait loci for IL1RN expression (and serum levels of IL-1Ra protein) and response to anakinra therapy in patients from the INCHARGE US population*

\begin{tabular}{lcccc}
\hline & \multicolumn{2}{c}{ Homozygote frequency } & & \\
\cline { 2 - 3 } SNP/effect allele (high expression) & $\begin{array}{c}\text { Nonresponder } \\
(\mathrm{n}=9)\end{array}$ & $\begin{array}{c}\text { Any responder } \\
(\mathrm{n}=29)\end{array}$ & $P$ & OR $(95 \% \mathrm{CI})$ \\
\hline rs55663133/- & 0.67 & 0.22 & $1.6 \times 10^{-2}$ & $7.0(1.3-36.7)$ \\
rs62158854/T & 0.67 & 0.22 & $1.6 \times 10^{-2}$ & $7.0(1.3-36.7)$ \\
rs62158853/C & 0.67 & 0.24 & $2.1 \times 10^{-2}$ & $6.3(1.2-32)$ \\
rs55709272/T & 0.67 & 0.1 & $9.8 \times 10^{-4}$ & $17.3(2.8-108.1)$ \\
rs7580634/G & 0.67 & 0.1 & $9.8 \times 10^{-4}$ & $17.3(2.8-108.1)$ \\
rs4251961/T & 0.78 & 0.21 & $1.8 \times 10^{-3}$ & $13.4(2.2-82)$ \\
rs555447483/- & 0.71 & 0.08 & $7.7 \times 10^{-4}$ & $28.7(3.2-255.8)$ \\
\hline
\end{tabular}

* IL-1Ra $=$ IL-1 receptor antagonist (see Table 1 for other definitions).

that individuals with the highest genetically encoded levels of IL-1Ra may be more likely to experience nonresponse to anakinra treatment than those with lower genetically encoded IL-1Ra levels. To evaluate this possibility, we examined clinical and SNP genotype data in 38 patients with systemic JIA from the US collection who had received anakinra and for whom clinical data were available. Within this group of anakinra-treated patients, there were 9 nonresponders and 29 "any responders." An examination of the top 7 systemic JIA-associated IL1RN SNPs revealed that for each SNP, homozygosity for the ILIRN high expression alleles was associated with nonresponse to anakinra treatment $(P<0.05)$ (Table 3). SNP rs555447483 showed the strongest association with nonresponsiveness to anakinra $\left(P=7.7 \times 10^{-4}\right.$; odds ratio 28.7 [95\% confidence interval 3.2-255.8]), with homozygous high expression alleles predicting nonresponse with a sensitivity of $92 \%$ and a specificity of $71 \%$.

In order to determine whether the relationship between these SNPs and nonresponsiveness to systemic JIA treatment was specific to anakinra, we performed an identical examination of the 14 patients with systemic JIA from the US case-control collection who were treated with tocilizumab (an anti-IL-6 monoclonal antibody). Within this group, which included 3 tocilizumab nonresponders and 11 tocilizumab "any responders," we found no association between systemic JIA-associated IL1RN SNPs and treatment response (see Supplementary Table 3, available on the Arthritis \& Rheumatology web site at http://onlinelibrary. wiley.com/doi/10.1002/art.40498/abstract). Moreover, 8 of the 14 patients who were treated with tocilizumab were anakinra nonresponders who had received tocilizumab as second-line treatment. Among the 8 anakinra nonresponders, 6 were tocilizumab "any responders." Taken together, these findings support the hypothesis that systemic JIA-associated ILIRN SNPs specifically predict nonresponsiveness of systemic JIA to anakinra treatment, as opposed to identifying individuals whose systemic JIA is more broadly refractory to treatment.

\section{DISCUSSION}

Through examination of common genetic variants at 11 previously reported systemic JIA susceptibility loci in the INCHARGE systemic JIA collection, this study has revealed 3 important findings. First, it has demonstrated that the ILIRN locus is a bona fide systemic JIA susceptibility locus. Second, the study has shown that genetically encoded high expression of ILIRN and production of IL$1 \mathrm{Ra}$ are protective against systemic JIA (and conversely that genetically encoded low expression and production are risk factors for developing the illness). Most importantly, it has shown that homozygosity for the high expression alleles of systemic JIA-associated ILIRN SNPs is strongly associated with nonresponsiveness to anakinra treatment in patients with systemic JIA.

The original studies that described these 11 candidate loci revealed modest associations that were identified in small case-control collections (7-16). At most of these loci, the associations with systemic JIA were not observed in subsequent studies of other populations, which calls into question their proposed relationships with systemic JIA. We sought to evaluate these associations more rigorously by using the INCHARGE systemic JIA collection, which provided greater statistical power than was present in any previous study of these loci while also allowing for internal validation through the examination of 9 independent populations.

Using this approach, we found that only 1 of these candidate loci, ILIRN, was associated with systemic JIA. At this locus, we observed 3 systemic JIA-associated SNPs that tagged a 7-SNP haplotype in the promoter region of IL1RN, as well as a cluster of 39 other SNPs with intermediate evidence of association with systemic 
JIA. Importantly, the $I L 1 R N$ association signal identified in the present study did not include any of the SNPs that were previously reported as being associated with systemic JIA (Table 1), or any SNPs that were in strong LD with those previously reported SNPs (Figure 1; also see Supplementary Figure 1, available on the Arthritis \& Rheumatology web site at http://onlinelibrary.wiley.com/doi/10. 1002/art.40498/abstract). This observation suggests that previous candidate gene studies of systemic JIA could have been negatively impacted by poor statistical power, as has been the case in studies of other genetically complex diseases, such as schizophrenia (28).

Given that the association signal of the IL1RN locus was within the promoter region, we hypothesized that these SNPs may influence systemic JIA risk by altering gene expression. By examining previously published gene expression studies and integrating our association data with publicly available gene expression data sets, we found that the risk alleles of the top 42 systemic JIA-associated $I L 1 R N$ SNPs correlated with reduced ILIRN expression and circulating IL-1Ra levels (Figure 2 and Table 2). Furthermore, we observed that the top 7 systemic JIAassociated SNPs were among the SNPs most strongly associated with $I L 1 R N$ expression levels in whole blood and LCLs, and with circulating levels of IL-1Ra protein, in previous studies (25-27) (Table 2). Taken together these observations suggest that the systemic JIA-associated $I L 1 R N$ SNPs influence systemic JIA risk through their effect on IL1RN expression and production of IL-1Ra.

IL-1Ra is a well-documented, positive, acute-phase protein (29) and it has been shown to be highly expressed in the blood of children with active systemic JIA $(30,31)$. Therefore, one would expect that gene expression studies would demonstrate increased expression of ILIRN in children with active systemic JIA as compared to healthy subjects or children with quiescent systemic JIA. There have been several studies that have examined gene expression in systemic JIA peripheral blood mononuclear cells. In 1 of these studies, the expression of positive acute-phase genes was up-regulated in children with systemic JIA and the authors noted that $I L 1 R N$ was among this cluster (32). However, 3 other studies showed no relationship between systemic JIA and IL1RN expression (33-35).

There are a few potential reasons for these conflicting results. It is possible that these studies lacked the statistical power to identify a relationship between systemic JIA and $I L 1 R N$ expression, given that they were undertaken in relatively small numbers of systemic JIA cases. It is also possible that these studies were affected by confounding variables that altered ILIRN expression in the systemic JIA patients, such as the duration of systemic JIA, the level of disease activity, or the treatment administered. In the present study, by examining the correlation between systemic JIA-associated ILIRN variants and gene expression in healthy individuals, we were able to identify the relationship between ILIRN expression and systemic JIA without the interference of these potential confounders.

In addition to evaluating disease risk, we demonstrated that high expression alleles of systemic JIAassociated ILIRN SNPs were strongly associated with nonresponsiveness to anakinra therapy. The lack of association between these SNPs and nonresponsiveness to tocilizumab treatment suggests that these SNPs are specifically associated with anakinra nonresponsiveness, as opposed to being associated with more global treatment resistance. In the context of the biphasic hypothesis of systemic JIA pathophysiology, new-onset systemic JIA is treated with the goal of rapidly inducing remission within the therapeutic window of opportunity (4).

Anakinra is commonly chosen as the first line treatment because its effects can be observed within days of treatment initiation and because dosing can be rapidly escalated, but it is not effective in all patients (36). In the subset of systemic JIA patients who ultimately do not respond to anakinra, the time to remission is prolonged due to the unsuccessful course of anakinra treatment. The findings of this study can be used to identify the subset of children with systemic JIA who are unlikely to respond to anakinra and to facilitate the selection of an alternative treatment. In doing so, the delay associated with a firstline therapeutic failure can be avoided, time to remission can be reduced, and unnecessary exposure to the risks of anakinra treatment can be prevented. ILIRN SNP genotypes are the first candidate biomarkers that can prospectively guide therapeutic decision-making in systemic JIA.

Despite the strength of the findings, it is important to consider the potential limitations of our study. The study evaluated genetic associations in 9 independent systemic JIA case-control collections. For future studies, it will be important to examine the ILIRN region in larger, independent groups of patients. There were also several limitations to the evaluation of genetic predictors of anakinra response. Therapeutic response to anakinra was examined in 38 systemic JIA patients, which is a relatively small group. The therapy regimen in anakinra-treated patients was not standardized, with potential variation in the drug dosing and duration, timing of dose escalation, and concurrent treatment with other agents (i.e., glucocorticoids). Additionally, the clinical response data were extracted from medical records in a post hoc analysis and clinical response metrics were not standardized. We anticipated that these factors would complicate differentiating incomplete and complete response, but should not influence the 
identification of nonresponsiveness. Therefore, we chose to compare nonresponse to "any response." Nonetheless, it will be important to evaluate the correlation between $I L 1 R N$ SNPs and response to anakinra in prospective studies of larger numbers of patients treated and monitored in a standardized manner.

By identifying a prospective biomarker capable of guiding the treatment of systemic JIA, this study brings precision medicine to rheumatology clinical practice. In future investigations, it will be important to determine whether these findings are generalizable beyond anakinra and systemic JIA. For example, can the IL1RN SNPs predict response to other IL-1-directed therapies, such as monoclonal anti-IL-1 $\beta$ antibodies (canakinumab) or the IL-1 trap (rilonacept), in systemic JIA? Similarly, these SNPs may predict therapeutic response to anakinra (or other IL-1-directed therapies) in conditions other than systemic JIA, such as adult-onset Still's disease or monogenic autoinflammatory diseases. Given that recently published reports have described studies in which canakinumab treatment significantly reduced the risk of recurrent cardiovascular events (37), as well as the incidence of and mortality from lung cancer (38), it is even possible that the utility of this prospective biomarker may extend beyond the field of rheumatology.

\section{ACKNOWLEDGMENTS}

The CAPS study was funded by Arthritis Research UK (20542). SPARKS-CHARMS was funded by grants from SPARKS UK (08ICH09 and 12ICH08) and the Medical Research Council (MR/M004600/1), and supported by the NIHR Biomedical Research Centres at Great Ormond Street Hospital for Children National Health Service Foundation Trust and University College London Hospitals Trust, and the NIHR-Clinical Research Network. The BBOP study was supported by the Canadian Institutes of Health Research (CIHR) and the Arthritis Society (CIHR funding reference number 82517) and the Canadian Arthritis Network (funding reference SRI-IJD-01). This research was supported in part by the Cincinnati Children's Research Foundation and its Cincinnati Genomic Control Cohort. The authors acknowledge the use of DNA from the UK Blood Services collection of Common Controls (funded by Wellcome Trust grant $076113 / \mathrm{C} / 04 / \mathrm{Z}$ and by the US NIH research program grant to the National Health Service Blood and Transplant [RP-PG-0310-1002]) and from the British 1958 Birth Cohort collection (funded by the UK Medical Research Council grant G0000934 and by Wellcome Trust grant 068545/Z/02). This work utilized the computational resources of the NIH High Performance Computing Biowulf cluster (http://hpc.nih.gov).

\section{AUTHOR CONTRIBUTIONS}

All authors were involved in drafting the article or revising it critically for important intellectual content, and all authors approved the final version to be published. Dr. Ombrello had full access to all of the data in the study and takes responsibility for the integrity of the data and the accuracy of the data analysis.

Study conception and design. Arthur, Shuldiner, Remmers, Ombrello. Acquisition of data. Arthur, Shuldiner, Remmers, Hinks, Grom, Foell, Martini, Gattorno, Ozen, Prahalad, Zeft, Bohnsack, Ilowite, Mellins, Russo, Len, Oliveira, Yeung, Rosenberg, Wedderburn, Anton, Haas, Rosen-Wolff, Minden, Thomson, Kastner, Woo, Ombrello.

Analysis and interpretation of data. Arthur, Shuldiner, Remmers, Szymanski, Thomson, Ombrello.

\section{REFERENCES}

1. Woo P. Systemic juvenile idiopathic arthritis: diagnosis, management, and outcome. Nat Clin Pract Rheumatol 2006;2:28-34.

2. Cimaz R. Systemic-onset juvenile idiopathic arthritis. Autoimmun Rev 2016;15:931-4.

3. Mellins ED, Macaubas C, Grom AA. Pathogenesis of systemic juvenile idiopathic arthritis: some answers, more questions. Nat Rev Rheumatol 2011;7:416-26.

4. Nigrovic PA. Is there a window of opportunity for treatment of systemic juvenile idiopathic arthritis? [review]. Arthritis Rheumatol 2014;66:1405-13.

5. Beukelman T. Treatment advances in systemic juvenile idiopathic arthritis. F1000Prime Rep 2014;6:21.

6. Janow G, Schanberg LE, Setoguchi S, Hasselblad V, Mellins ED, Schneider R, et al, CARRA Legacy Registry Investigators. The Systemic Juvenile Idiopathic Arthritis Cohort of the Childhood Arthritis and Rheumatology Research Alliance Registry: 20102013. J Rheumatol 2016;43:1755-62.

7. Stock CJ, Ogilvie EM, Samuel JM, Fife M, Lewis CM, Woo P Comprehensive association study of genetic variants in the IL-1 gene family in systemic juvenile idiopathic arthritis. Genes Immun 2008;9:349-57.

8. Hinks A, Martin P, Thompson SD, Sudman M, Stock CJ, Thomson W, et al. Autoinflammatory gene polymorphisms and susceptibility to UK juvenile idiopathic arthritis. Pediatr Rheumatol Online J 2013;11:14.

9. Fife MS, Gutierrez A, Ogilvie EM, Stock CJ, Samuel JM, Thomson W, et al. Novel IL10 gene family associations with systemic juvenile idiopathic arthritis. Arthritis Res Ther 2006;8:R148.

10. Omoyinmi E, Forabosco P, Hamaoui R, Bryant A, Hinks A, Ursu $\mathrm{S}$, et al. Association of the IL-10 gene family locus on chromosome 1 with juvenile idiopathic arthritis (JIA). PLoS One 2012;7:e47673.

11. Fishman D, Faulds G, Jeffery R, Mohamed-Ali V, Yudkin JS, Humphries S, et al. The effect of novel polymorphisms in the interleukin-6 (IL-6) gene on IL-6 transcription and plasma IL-6 levels, and an association with systemic-onset juvenile chronic arthritis. J Clin Invest 1998;102:1369-76.

12. Ogilvie EM, Fife MS, Thompson SD, Twine N, Tsoras M, Moroldo $\mathrm{M}$, et al. The $-174 \mathrm{G}$ allele of the interleukin-6 gene confers susceptibility to systemic arthritis in children: a multicenter study using simplex and multiplex juvenile idiopathic arthritis families. Arthritis Rheum 2003;48:3202-6.

13. Scheibel I, Veit T, Neves AG, Souza L, Prezzi S, Machado S, et al. Differential CCR5 32 allelic frequencies in juvenile idiopathic arthritis subtypes: evidence for different regulatory roles of CCR5 in rheumatological diseases. Scand J Rheumatol 2008;37:13-7.

14. De Benedetti F, Meazza C, Vivarelli M, Rossi F, Pistorio A, Lamb R, et al. Functional and prognostic relevance of the -173 polymorphism of the macrophage migration inhibitory factor gene in systemic-onset juvenile idiopathic arthritis. Arthritis Rheum 2003;48:1398-407.

15. Lamb R, Thomson W, Ogilvie EM, Donn R. Positive association of SLC26A2 gene polymorphisms with susceptibility to systemic-onset juvenile idiopathic arthritis. Arthritis Rheum 2007;56:1286-91.

16. Bukulmez H, Fife M, Tsoras M, Thompson SD, Twine NA, Woo $\mathrm{P}$, et al. Tapasin gene polymorphism in systemic onset juvenile 
rheumatoid arthritis: a family-based case-control study. Arthritis Res Ther 2005;7:R285-90.

17. Ombrello MJ, Remmers EF, Tachmazidou I, Grom A, Foell D, Haas JP, et al. HLA-DRB1*11 and variants of the MHC class II locus are strong risk factors for systemic juvenile idiopathic arthritis. Proc Natl Acad Sci U S A 2015;112:15970-5.

18. Ombrello MJ, Arthur VL, Remmers EF, Hinks A, Tachmazidou I, Grom AA, et al. Genetic architecture distinguishes systemic juvenile idiopathic arthritis from other forms of juvenile idiopathic arthritis: clinical and therapeutic implications. Ann Rheum Dis 2017;76:906-13.

19. Marchini J, Howie B, Myers S, McVean G, Donnelly P. A new multipoint method for genome-wide association studies by imputation of genotypes. Nat Genet 2007;39:906-13.

20. Magi R, Morris AP. GWAMA: software for genome-wide association meta-analysis. BMC Bioinformatics 2010;11:288.

21. Barrett JC, Fry B, Maller J, Daly MJ. Haploview: analysis and visualization of LD and haplotype maps. Bioinformatics 2005;21: 263-5.

22. Purcell S, Neale B, Todd-Brown K, Thomas L, Ferreira MA, Bender D, et al. PLINK: a tool set for whole-genome association and population-based linkage analyses. Am J Hum Genet 2007;81:559-75.

23. Ward LD, Kellis M. HaploReg v4: systematic mining of putative causal variants, cell types, regulators and target genes for human complex traits and disease. Nucleic Acids Res 2016;44:D877-81.

24. 1000 Genomes Project Consortium, Auton A, Brooks LD, Durbin RM, Garrison EP, Kang HM, et al. A global reference for human genetic variation. Nature 2015;526:68-74.

25. Lappalainen T, Sammeth M, Friedlander MR, 't Hoen PA, Monlong J, Rivas MA, et al. Transcriptome and genome sequencing uncovers functional variation in humans. Nature 2013;501:506-11.

26. Westra HJ, Peters MJ, Esko T, Yaghootkar H, Schurmann C, Kettunen J, et al. Systematic identification of trans eQTLs as putative drivers of known disease associations. Nat Genet 2013; 45:1238-43.

27. Herder C, Nuotio ML, Shah S, Blankenberg S, Brunner EJ, Carstensen $\mathrm{M}$, et al. Genetic determinants of circulating interleukin-1 receptor antagonist levels and their association with glycemic traits. Diabetes 2014;63:4343-59.

28. Farrell MS, Werge T, Sklar P, Owen MJ, Ophoff RA, O'Donovan $\mathrm{MC}$, et al. Evaluating historical candidate genes for schizophrenia. Mol Psychiatry 2015;20:555-62.

29. Gabay C, Gigley J, Sipe J, Arend WP, Fantuzzi G. Production of IL-1 receptor antagonist by hepatocytes is regulated as an acutephase protein in vivo. Eur J Immunol 2001;31:490-9.

30. Prieur AM, Kaufmann MT, Griscelli C, Dayer JM. Specific interleukin-1 inhibitor in serum and urine of children with systemic juvenile chronic arthritis. Lancet 1987;2:1240-2.

31. De Benedetti F, Pignatti P, Massa M, Sartirana P, Ravelli A, Martini A. Circulating levels of interleukin $1 \beta$ and of interleukin 1 receptor antagonist in systemic juvenile chronic arthritis. Clin Exp Rheumatol 1995;13:779-84.

32. Fall N, Barnes M, Thornton S, Luyrink L, Olson J, Ilowite NT, et al. Gene expression profiling of peripheral blood from patients with untreated new-onset systemic juvenile idiopathic arthritis reveals molecular heterogeneity that may predict macrophage activation syndrome. Arthritis Rheum 2007;56:3793-804

33. Ogilvie EM, Khan A, Hubank M, Kellam P, Woo P. Specific gene expression profiles in systemic juvenile idiopathic arthritis. Arthritis Rheum 2007;56:1954-65.

34. Barnes MG, Grom AA, Thompson SD, Griffin TA, Pavlidis P, Itert L, et al. Subtype-specific peripheral blood gene expression profiles in recent-onset juvenile idiopathic arthritis. Arthritis Rheum 2009;60:2102-12.

35. Macaubas C, Nguyen KD, Peck A, Buckingham J, Deshpande C, Wong E, et al. Alternative activation in systemic juvenile idiopathic arthritis monocytes. Clin Immunol 2012;142:362-72.

36. Gattorno M, Piccini A, Lasiglie D, Tassi S, Brisca G, Carta S, et al. The pattern of response to anti-interleukin-1 treatment distinguishes two subsets of patients with systemic-onset juvenile idiopathic arthritis. Arthritis Rheum 2008;58:1505-15.

37. Ridker PM, Everett BM, Thuren T, MacFadyen JG, Chang WH, Ballantyne $\mathrm{C}$, et al. Antiinflammatory therapy with canakinumab for atherosclerotic disease. N Engl J Med 2017;377:1119-31.

38. Ridker PM, MacFadyen JG, Thuren T, Everett BM, Libby P, Glynn RJ, et al. Effect of interleukin-1 $\beta$ inhibition with canakinumab on incident lung cancer in patients with atherosclerosis: exploratory results from a randomised, double-blind, placebocontrolled trial. Lancet 2017;390:1833-42.

\section{APPENDIX A: FULL MEMBERSHIP OF THE INTERNATIONAL CHILDHOOD ARTHRITIS GENETICS (INCHARGE) CONSORTIUM}

INCHARGE Consortium members. Jean-Paul Achkar (Cleveland, $\mathrm{OH}$ ), Marta E. Alarcón-Riquelme (Granada, Spain and Solna, Sweden), Jordi Anton (Barcelona, Spain), Victoria L. Arthur (Bethesda, MD), Elizabeth Baskin (Bethesda, MD), John F. Bohnsack (Salt Lake City, UT), Joanna Cobb (Manchester, UK), Erkan Demirkaya (Ankara, Turkey), Elisa Docampo (Liège, Belgium and Barcelona, Spain), Richard H. Duerr (Pittsburgh, PA), Xavier Estivill (Barcelona, Spain and Doha, Qatar), Dirk Foell (Münster, Germany), Marco Gattorno (Genoa, Italy), Alexei Grom (Cincinnati, OH), Ahmet Gül (Istanbul, Turkey), Maria Odete E. Hilario (São Paulo, Brazil), Norman T. Ilowite (Bronx, NY), Johannes-Peter Haas (Garmisch-Partenkirchen, Germany), Anne Hinks (Manchester, UK), M. Ilyas Kamboh (Pittsburgh, PA), Daniel L. Kastner (Bethesda, MD), Kenneth M. Kaufman (Cincinnati, OH), Leah C. Kottyan (Cincinnati, OH), Carl D. Langefeld (Winston-Salem, NC), Claudio Len (São Paulo, Brazil), Alberto Martini (Genoa, Italy), Elizabeth D. Mellins (Stanford, CA), Kirsten Minden (Berlin, Germany), Sheila Oliveira (Rio de Janeiro, Brazil), Michael J. Ombrello (Bethesda, MD), Seza Özen (Ankara, Turkey), Dalila Pinto (New York, NY), Sampath Prahalad (Atlanta, GA), Elaine F. Remmers (Bethesda, MD), Angela Rosen-Wolff (Dresden, Germany), Alan Rosenberg (Saskatoon, Canada), Ricardo Russo (Buenos Aires, Argentina), Stephen W. Scherer (Toronto, Canada), Sara Signa (Genoa, Italy), Emily Shuldiner (Bethesda, MD), Ann Marie Szymanski (Bethesda, MD), Ioanna Tachmazidou (Hinxton, UK), Klaus Tenbrock (Aachen, Germany), Susan Thompson (Cincinnati, OH), Wendy Thomson (Manchester, UK), Lucy R. Wedderburn (London, UK), Patricia Woo (London, UK), Rae S. M. Yeung (Toronto, Canada), Andrew S. Zeft (Cleveland, OH), Eleftheria Zeggini (Hinxton, UK), Biologically Based Outcome Predictors in JIA (BBOP) Group, British Society of Pediatric and Adolescent Rheumatology (BSPAR) Study Group, Childhood Arthritis Prospective Study (CAPS) Group, Inception Cohort of Newly Diagnosed Patients with Juvenile Idiopathic Arthritis (ICON-JIA), Randomized Placebo Phase Study of Rilonacept in sJIA (RAPPORT) Investigators, and the Sparks-Childhood Arthritis Response to Medication Study (CHARMS) Group.

Biologically Based Outcome Predictors in JIA group. Adam Baxter-Jones (Saskatoon, Canada), Susanne Benseler (Toronto, Canada), Gilles Boire (Sherbrooke, Canada), David A. Cabral (Vancouver, Canada), Bonnie Cameron (Toronto, Canada), Sarah Campillo (Montreal, Canada), Gaëlle Chédeville (Montreal, Canada), Anne-Laure Chetaille (Quebec, Canada), Paul Dancey (St. John's, Canada), Ciaran Duffy (Ottawa, Canada), Karen Watanabe Duffy (Ottawa, Canada), Janet Ellsworth (Edmonton, Canada), Michele Gibbon (Ottawa, Canada), Chantal Guillet (Quebec, Canada), Jaime Guzman (Vancouver, Canada), Kristin Houghton (Vancouver, Canada), Adam M. Huber (Halifax, Canada), Roman Jurencak (Ottawa, Canada), Bianca Lang (Halifax, Canada), Ronald M. Laxer (Toronto, Canada), Lynn Maenz (Saskatoon, Canada), Loren Matheson (Saskatoon, Canada), Kiem G. Oen (Winnipeg, Canada), Ross E. Petty (Vancouver, Canada), Suzanne E. Ramsey (Halifax, Canada), Elham Rezaei (Saskatoon, Canada), Alan M. Rosenberg (Saskatoon, Canada), Johannes Roth (Ottawa, Canada), Rayfel Schneider (Toronto, Canada), Rosie Scuccimarri (Montreal, Canada), Stephen W. 
Scherer (Toronto, Canada), Earl Silverman (Toronto, Canada), Lynn Spiegel (Toronto, Canada), Elizabeth Stringer (Halifax, Canada), Shirley M. L. Tse (Toronto, Canada), Lori B. Tucker (Vancouver, Canada), Stuart Turvey (Vancouver, Canada), Richard F. Wintle (Toronto, Canada), Rae S. M. Yeung (Toronto, Canada).

British Society of Pediatric and Adolescent Rheumatology Study Group. Mario Abinum (Newcastle, UK), A. Bell (Belfast, UK), Alan W. Craft (Newcastle, UK), Esther Crawley (London, UK), Joel David (Oxford, UK), Helen Foster (London, UK), Janet GardenerMedwin (Glasgow, UK), Jane Griffin (London, UK), Ann Hall (Berkshire, UK) M. Hall (Cardiff, UK), Ariane L. Herrick (Salford, UK), Peter Hollingworth (Bristol, UK), Lennox Holt (Manchester, UK), Stan Jones (Lancashire, UK), Gillian Pountain (Cambridgeshire, UK), Clive Ryder (Birmingham, UK), Tauny Southwood (Birmingham, UK), I. Stewart (Lancashire, UK), Helen Venning (Nottingham, UK), Lucy R. Wedderburn (London, UK), Patricia Woo (London, UK), Sue Wyatt (Leeds, UK).

Childhood Arthritis Prospective Study group. Eileen Baildam (Liverpool, UK), Nick Bishop (Sheffield, UK), Lynsey Brown (Liverpool, UK), Joanne Buckley (Manchester, UK), Alice Chieng (Manchester, UK), Roberto Carrasco (Manchester, UK), Joanna Cobb (Manchester, UK), Lucy Cook (Newcastle, UK), Joyce Davidson (Edinburgh, UK and Glasgow, UK), Annette Duggan (Manchester, UK), Michael Eltringham (Newcastle, UK), Helen Foster (Newcastle, UK), Elizabeth Friel (Glasgow, UK), Mark Friswell (Newcastle, UK), Janet Gardner-Medwin (Glasgow, UK), Paul Gilbert (Manchester UK), Vikki Gould (Edinburgh, UK), Kelly Hadfield (Manchester UK), Kimme Hyrich (Manchester, UK), Julie Jones (London, UK), Sham Lal (Manchester, UK), Mark Lay (Manchester, UK), Gabrielle Lloyd (Liverpool, UK), Olivia Lloyd (Liverpool, UK), Carol Lydon (Liverpool, UK), Natasha Makengo (London, UK), Ann McGovern (Manchester, UK), Alexandra Meijer (London, UK), Nicola Mills-Wierda (Glasgow, UK), Theresa Moorcroft (Liverpool, UK), Vicki Price (Glasgow, UK), Liang Qiao (Newcastle, UK), Kay Riding (Edinburgh, UK), Jane Sim (Glasgow, UK), Tauny Southwood (Birmingham, UK), Wendy Thomson (Manchester, UK), Maureen Todd (Glasgow, UK), Susan Tremble (Liverpool, UK), Katharine Venter (Liverpool, UK), Debbie Wade (Newcastle, UK), Peter Ward (Manchester, UK), Sharon Watson (Glasgow, UK), Gwen Webster (Liverpool, UK), Lucy R Wedderburn (London, UK), Jadranka Zelenovic (Glasgow, UK).
Inception Cohort of Newly Diagnosed Patients with Juvenile Idiopathic Arthritis Study Group. Ivan Foeldvari (Hamburg, Germany), Dirk Foell (Münster, Germany), Gerd Ganser (Seldenhorst, Germany), Johannes-Peter Haas (Partenkirchen, Germany), Arnd Heiligenhaus (Essen, Germany), Gerd Horneff (Sankt Augustin, Germany), Anton Hospach (Stuttgart, Germany), Hans-Iko Huppertz (Bremen, Germany), Tilmann Kallinich (Berlin, Germany), Jasmin Kümmerle-Deschner (Tübingen, Germany), Kirsten Minden (Berlin, Germany), Kirsten Mönkemöller (Köln, Germany), Angelika Thon (Hannover, Germany).

Randomized Placebo Phase Study of Rilonacept in SJIA investigators. James D. Birmingham (East Lansing, MI), Melissa Elder (Gainesville, FL), Beth S. Gottlieb (New York, NY), Normal T. Ilowite (Bronx, New York), Lisa F. Imundo (New York, NY), Yukiko Kimura (Hackensack, NJ), Yuliya Lokhnygina (Durham, NC), Michael L. Miller (Chicago, IL), Diana Milojevic (San Francisco, CA), Kathleen O'Neil (Indianapolis, IN), Marilynn G. Punaro (Dallas, TX), Kristi Prather (Durham, NC), Natasha M. Ruth (Charleston, SC), Christy I. Sandborg (Stanford, CA), Laura E. Schanberg (Durham, NC), David D. Sherry (Philadelphia, PA), Nora G. Singer (Cleveland, OH), Steven J. Spalding (Cleveland, OH), Stacey E. Tarvin (Indianapolis, IN), James W. Verbsky (Milwaukee, WI), Carol A. Wallace (Seattle, WA), Lawrence S. Zemel (Hartford, CT).

Sparks-Childhood Arthritis Response to Medication Study group. Kate Armon (Birmingham, UK and Cambridge, UK), Katrin Burkle (London, UK), Joanna Cobb (Manchester, UK), Rebecca Cutts (Southampton, UK), Angela Etheridge (London, UK), Eirini Giannakopoulou (London, UK), Paul Gilbert (Manchester, UK), Anne Hinks (Manchester, UK), Shashi Hirani (London, UK), Clare Heard (London, UK), Ruth Howman (Birmingham, UK), Cerise Johnson (London, UK), Laura Kassoumeri (London, UK), Sham Lal (Manchester, UK), Alice Leahy (Southampton, UK), Lucy Marshall (London, UK), Laura Melville (London, UK), Halima Moncrieffe (London, UK), Kathleen Mulligan (London, UK), Stanton Newman (London, UK), Jason Palman (London, UK), Fiona Patrick (London, UK), Emily Robinson (London, UK), Stephanie Simou (London, UK), Stefanie Stafford (Nottingham, UK), Tauny Southwood (Birmingham, UK), Wendy Thomson (Manchester, UK), Petra Tucker (Cambridge, UK), Simona Ursu (London, UK), Kishore Warrier (Nottingham, UK), Joanna Watts (Birmingham, UK), Lucy R. Wedderburn (London, UK), Pamela Whitworth (Birmingham, UK), Patricia Woo (London, UK). 